\title{
Two green bottles leave physicists hanging
}

Paris. An act of sabotage involving two strategically placed beer bottles has delayed the start of a major new phase of experiments in the Large ElectronPositron Collider (LEP) at the European Laboratory for Particle Physics (CERN) in Geneva, Switzerland.

Physicists at CERN spent last winter upgrading the 90-GeV LEP to transform it into a 161-GeV machine, LEP2, which is expected to open up possibilities for a new series of discoveries. But when the machine was switched on for the first time on 14 June, they were unable to obtain either an electron or a positron beam.

The problem was first put down to teething troubles. But it was quickly found to be the results of a more sinister cause, namely a blockage somewhere in the $27-\mathrm{km}$ tunnel. Tests narrowed down the location of the obstacle to a 10-metre stretch of the beam pipe, which was dismantled to reveal two empty Heineken bottles, placed 5 metres apart.

While CERN officials joke about Heineken's advertising slogan - that it "reaches the parts other beers can't reach" - they are taking the incident extremely seriously. Police have been called in to investigate and to take fingerprints from the bottles. This is the only way the culprit is likely to be traced, says one CERN official, who adds that it is still not clear whether the act was malicious or simply intended as a prank.

The sabotage is a serious setback, as the five-day delay it has caused will reduce by almost 10 per cent the time available this summer for running LEP2 at the new energy level. This energy is expected to produce the first pairs of fundamental particles of $W^{+}$and $W^{-}$. If the bottles had not been found as quickly as they were, then the impact of the delay would have even more serious.

CERN has tightened security following another incident last year, where a deranged technician cut cables and removed 1,200 components from the LEP accelerator. This sabotage put the accelerator out of action for months (see Nature 373,$650 ; 1995$ ). But officials say that the site is just too big to make it secure against all possible attacks. Declan Butler

\section{China focuses research efforts on grain production}

Hong Kong. The Chinese government has announced a 10-billion-yuan five-year programme of support for research projects that can demonstrate an influence on "economic and social development". Onethird of the 15 selected projects concentrate on agriculture, including proposals to increase crop yields and promote intensive farming, as well as research into new pesticides and fertilizers.

China's ability to feed itself is a matter of great concern both internally and to the rest of the world. Its commitment to becoming self-sufficient in grain broke down in 1994, when China became a net importer, despite being the world's largest wheat producer. Last August, the Chinese Academy of Sciences predicted that the situation will get worse, with the shortfall of grain reaching 40 million tonnes by the year 2000 , and 50 million tonnes - 10 per cent of present consumption - by 2020.

The announcement of the new funding by Deng Nan, vice-minister at the State Science and Technology Commission, appears to be part of a package of measures designed to boost investment in agriculture. It was followed, first, by a decision by China's central government to increase investment in agriculture overall over the next five years, and, two days later, by a speech from Li Peng, the premier, calling for the increased application of science and technology, particularly in agriculture.

At the end of May, more than 1,500 Chinese science representatives and government officials gathered in Beijing for a five-yearly congress at which research priorities for the next five years were agreed. The congress decided that one priority should be agricultural research aimed at increasing crop yields.
The congress was organized by the China Association for Science and Technology (CAST), an umbrella group for about 200 professional bodies and research institutes, including the Chinese Academy of Sciences. It was followed by congresses of individual academies, such as those of science and

\section{IMAGE UNAVAILABLE FOR COPYRIGHT REASONS}

Taking the strain: modernization of agriculture has become a priority for China's political leaders.

engineering. Although CAST is a nonpolicy-making body, government officials including President Jiang Zemin - participated in the congress, giving it a major role in mapping out the future direction of science.

The problem is not only one of growing numbers of people and poorly paid farmers who are deserting rural areas for better paid jobs in the cities, but also the fact that demand for a more varied diet has led to more grain being used to feed livestock. Furthermore, although the central government has made extensive investment in agriculture, local leaders are often keen to sell off land for more profitable industrial production. As a result, rice production has fallen by seven per cent since 1990 .

Jiang Chunyun, the vice-premier, told the meeting a 35 per cent increase in the country's agricultural output had been achieved through science since 1979. But, he said, the agricultural sector still needs more modern techniques.

The day after the five-day meeting ended, the State Science and Technology Commission announced the formation of the National Corn Engineering Technique ¿ Research Centre in Shandong \& province, intended to import and breed strains of corn seeds and to improve cultivation.

Many institutes around the country study new genetic strains or crossbreeds of grain, and China holds one of the world's largest wheatgerm banks. The government has invested billions of dollars in its 'Spark' research programme, started in 1986 to modernize agriculture through the application of science and technology (see Nature 378, 537: 1995). But field testing of new crops is often primitive by Western standards.

For example, the potential dangers of releasing new genetic strains into the environment are said to be often ignored.

CAST claims that, in the past five years, with the help of various science groups and associations, it has disseminated scientific information and techniques to more than 200 million farmers, and it plans to educate another 200 million of China's approximately 800 million farmers over the next five years.

But much of this work, led by the Chinese Academy of Sciences, the Chinese Academy of Agricultural Sciences and the Rural Development Institute of the Chinese Academy of Social Sciences, is not very scientific, and focuses on basic problems such as more efficient fertilizer use - which farmers tend to overuse in a bid to push up yields - better irrigation, and increasing the size of the tiny plots each family at present ploughs.

Elisabeth Tacey 